\title{
A origem judaico-cristã do paradigma da governamentalidade e sua pertinência para uma análise do neoliberalismo atual
}

\author{
Karolayne Maria V. C. de Moraes* \\ Alex da Silva Mendes**
}

\begin{abstract}
RESUMO
O presente artigo versa sobre a noção de governamentalidade proposta por Foucault e a pertinência desse conceito como "pedra de toque" para a realização de uma boa análise e compreensão da realidade atual. Num primeiro momento, a pesquisa se volta para a aula do dia oito de fevereiro de 1978, ministrada por Foucault, no Collège de France, em que o mesmo apresenta como a origem de uma das mais eficazes estratégias de governo dos homens remonta a um paradigma judaico-cristão, a do pastor que conduz as suas ovelhas. Em seguida, buscar-se-á apresentar como o mesmo paradigma, base da governamentalidade de outrora, permanece vigente na realidade atual, ainda que com a utilização de outros instrumentais, porém com as mesmas finalidades de dirigir as consciências e as condutas à uma assimilação da ordem neoliberal cada vez mais incisiva. Objetiva-se, portanto, por meio desse artigo compreender qual é o paradigma base da noção de governamentalidade apresentada por Foucault e como esse mesmo paradigma mostra-se ainda hoje atuante e eficaz, no contexto hodierno, exercendo seu poder e vigilância sobre a conduta dos sujeitos que respondem de modo passivo.
\end{abstract}

Palavras-chaves: Foucault; Governamentalidade; Pastor; Ovelhas; Atualidade

* Mestranda em Teologia (Pontifícia Universidade Católica de São Paulo, PUC-SP). Bacharel em Teologia pela PUC-SP. Membra dos grupos de pesquisa José Comblin (GPJC); Pessoa Humana Antropologia Ética e Sexualidade (PHAES). E-mail: karolaynecamargo18@ gmail.com

** Mestrando em Teologia (Pontifícia Universidade Católica de São Paulo, PUC-SP). Membro do Grupo de Pesquisa Lerte (Pesquisa em Literatura, Religião e Teologia), da Sociedade Paul Tillich do Brasil e A Questão de Deus. E-mail: professoralex.educacao@, gmail.com 


\title{
THE JEWISH-CHRISTIAN ORIGIN OF THE GOVERNMENTALITY PARADIGM AND ITS RELEVANCE TO AN ANALYSIS OF CURRENT NEOLIBERALISM
}

\begin{abstract}
This paper works with Foucault's governmentality concept and the relevance of this concept as a "touchstone" for carrying out a good analysis and understanding of current reality. At first, the research turns to the class on February 8, 1978, delivered by Foucault, at the Collège de France, in which he presents how the origin of one of the most effective strategies for the government of men goes back to a paradigm Judeo-Christian, that of the shepherd who leads his sheep. Then, it will be sought to present how the same paradigm, the basis of governmentality of yore, remains in force in the current reality, albeit with the use of other instruments, but with the same purposes of directing consciences and behavior towards an assimilation of the increasingly incisive neoliberal order. The objective, therefore, through this article is to understand the basic paradigm of the notion of governmentality presented by Foucault and how this same paradigm is still active and effective today, in today's context, exercising its power and vigilance over the conduct of subjects that respond in a passive way.
\end{abstract}

Keywords: Foucault; Governmentality; Shepherd; Sheep; State

\section{Introdução}

Atualmente, muito se fala sobre a realidade do governo, porém grande parte destas vozes partem do próprio contexto hodierno, sem levar em conta as raízes históricas que o termo possui, ou ainda, qual a origem e a lógica que o subjaz. Corajosamente, Foucault, em um dos seus cursos ministrados no Collège de France, em 1978, se propõe o percurso inverso do que ocorre hoje. Após uma robusta pesquisa, o filósofo aponta com muita precisão as origens do paradigma que determina ainda hoje o que ele chama de "governamentalidade", ou seja, de tudo aquilo que se relaciona ao governo. De modo particular, Foucault expõe qual a lógica assumida para a gestão dos Estados e como suas origens remontam à prática religiosa cristã da condução pastoral. Isso, porque, a referida prática tem como base a ideia religiosa do pastor que conduz 
o seu rebanho, que conhece e governa não apenas o todo, mas cada uma das ovelhas, o que, para Foucault, é uma das estratégias mais eficazes de vigilância e controle da história, e que ainda continua subjacente, embora com outra roupagem e instrumentais, incidindo sobre a consciência das pessoas e, por conseguinte, determinando as suas condutas.

É importante enfatizar, que Foucault (FOUCAULT, 2008, p. 143144) ${ }^{1}$, define assim a governamentalidade: “[...] conjunto constituído pelas instituições, os procedimentos, análises e reflexões, os cálculos e as táticas que permitem exercer essa forma bem específica, embora muito complexa, de poder que tem por alvo principal a população, por principal forma de saber a economia política e por instrumento técnico essencial os dispositivos de segurança. Em segundo lugar, por "governamentalidade" entendo a tendência, a linha de força que, em todo o Ocidente, não parou de conduzir, e desde há muito, para a preeminência desse tipo de poder que podemos chamar de 'governo' sobre todos os outros- soberania, disciplina- e que trouxe, por um lado, o desenvolvimento de toda uma serie de aparelhos específicos de governo [e por outro lado], o desenvolvimento de toda uma serie de saberes. Enfim, por "governamentalidade" creio que se deveria entender o processo, ou antes, o resultado do processo pela qual o Estado de justiça da Idade Média, que nos séculos XV e XVI se tornou o Estado administrativo, viu-se pouco a pouco "governamentalidade".

A partir desses conceitos, percebe-se que governamentalidade tem a ver com o processo de formação histórica das práticas reflexivas de governo, desde a emergência do poder pastoral até o neoliberalismo.

Em linhas gerais, à governamentalidade procura responder a inquietante pergunta: como, e sob quais condições os sujeitos devem ser governados?

Foucault vai demonstrar que a biopolítica faz parte de uma governamentalidade. Que ainda existe em nosso presente, na forma da governamentalidade neoliberal. A governamentalidade é produzida por meio da história de um processo de governamentalização. O que hoje conhecemos como governo, é um conjunto de forças vinculadas a for-

1 FOUCAULT, M. Segurança, território e população. Tradução: Eduardo Brandão. São Paulo: Martins Fontes. 
ma de saber cuja forma dominante é a economia política, segundo Foucault, e um duplo objeto sujeito, denominado a população, o alvo do governo. Visto em determinado momento como origem do próprio do governo, e como seu produto também, porque a população, é vista como algo maximizado, libertada de seus aspectos "ruins", e as técnicas de racionalização, ou os dispositivos de segurança que informam a racionalização da vida cotidiana; como a burocratização, a gestão e outros processos administrativos de controle racional, que igualam a racionalidade e a liberdade, e, portanto, produzem um tipo específico de liberdade controlada. A governamentalidade é a naturalização desses processos de gestão econômica da sociedade civil pelo Estado.

\section{A noção de governamentalidade e seu paradigma base segundo Michel Foucault}

Uma vez analisadas as raízes históricas da noção de governo, na aula do dia primeiro de fevereiro de 1978, Foucault se detém, na aula do dia oito de fevereiro do mesmo ano, sobre a dimensão daquilo que ele chamou de "governamentalidade". Segundo ele, tendo como pressuposto que há uma especificidade daquilo que seja governar, e que, portanto, essa arte não é a mesma coisa que "reinar", "comandar", "ser juiz" etc., logo precisamos saber qual o tipo de poder que essa noção abarca (FOUCAULT, 2002, p. 155-156)2.

Em outras palavras, trata-se, segundo o filósofo, de analisar as relações de poder que estavam presentes tanto no século XVI, nas artes de governar desse período, como no séc. XVII, nas que se praticavam no período do mercantilismo, e que, por fim, constituem a doutrina do "governo econômico". A razão de ser dessa análise corresponde, para Foucault, a chegar ao cerne da noção de Estado e população, que apesar de muitos suporem conhecer, não parece que tudo já esteja explícito, mas há ainda uma parte imensa e obscura, na qual o filósofo pretende se deter a partir da noção de governamentalidade.

Para explicitar melhor a razão disso, ele diz que, nas aulas em que trabalhou a respeito das disciplinas, a propósito do exército, hospitais, prisões, escolas etc., seu objetivo consistia em realizar um tríplice deslocamento, ou melhor, passar para o exterior de três maneiras. Primeiro,

2 FOUCAULT, Michel. Segurança, território, população: curso dado no Collège de France (1977-1978). São Paulo: Martins Fontes, 2008. Aula do dia 8 de fevereiro, pp. 154-174. 
passar para o exterior da instituição, descentralizar-se em relação à problemática da mesma, ao que chamou de "institucional-centrismo".

Foucault, dá um exemplo desse modo de proceder com relação a um hospital psiquiátrico. Ele diz que podemos falar desse a partir do seu interior, de como se organizam as estruturas internas, o saber psiquiátrico que ali se desenvolve, ou coisa do tipo, porém podemos falar desse mesmo hospital a partir de uma visão externa, ou seja, buscando apresentar como o hospital enquanto instituição só pode ser compreendido a partir de algo exterior que é a ordem psiquiátrica, na medida em que essa está articulada à um projeto global maior que pode ser intitulado de "higiene pública". Assim, o método de passar para o exterior da instituição consiste em buscar, por detrás da instituição e mais globalmente que ela, o que Foucault chama de tecnologia de poder (FOUCAULT, 2002, p. 157) ${ }^{3}$.

Em segundo lugar, uma passagem ao exterior em relação à função. Trata-se de estudar a disciplina, por exemplo, no caso da prisão, analisando-a não a partir das funções esperadas, daquelas que foram definidas como ideais, mas, sim, passando para o exterior em relação a esse ponto de vista funcional e, então, situando novamente a prisão dentro de uma economia geral de poder. Trata-se, assim, de substituir o ponto de vista interno da função pelo externo das estratégias e táticas em que determinada instituição se apoia.

A terceira e última passagem ao exterior é em relação ao objeto. Quando parte do estudo das disciplinas, Foucault diz que se pressupõe a recusa da adoção de um objeto já pronto, dado, seja ele qual fosse (doença mental, sexualidade etc.), opondo-se a medir as instituições práticas e saberes de acordo com essas referências, senão que o intuito era bem outro. Tratava-se, ao contrário, de aprender o movimento pelo qual se consolidava, através dessas tecnologias movediças, um campo de verdade com objetos de saber (FOUCAULT, 2002, p. 158)4.

Em suma, dirá Foucault, seu ponto de vista adotado consistia em buscar destacar as relações de poder da instituição, para analisá-las sob o prisma das tecnologias; destacá-las da função, para retomá-las

\footnotetext{
Ibid., 157.

4 Ibid., 158.
} 
numa análise estratégica; e, por fim, destacá-las do objeto, na busca de ressituá-las a partir da constituição dos campos, domínios e objetos do saber.

Serão esses três movimentos de passagens para o exterior, realizadas com base no estudo das disciplinas, que Foucault tentará realizar a respeito do Estado. Passar para o exterior do Estado. Todavia o autor se pergunta se haverá um ponto de vista abrangente como o das disciplinas, que possibilite esse tipo de análise, ou ainda, se essas tecnologias gerais de poder das instituições não estão elas mesmas na dependência de uma instituição global, a saber, do Estado. Assim, o objeto próprio da análise de Foucault na presente aula corresponde a falar de algo como a governamentalidade, que seria para o Estado o que as tendências de segregação foram para a psiquiatria, as técnicas da disciplina, para o sistema penal e a biopolítica, para as instituições médicas.

Seu primeiro passo rumo a esse objetivo é situar-se brevemente na própria história da noção de governo, quando essa ainda não tinha adquirido conotação política, entre os sécs. XVI-XVII. Com base nos dicionários franceses, Foucault destaca que o termo abrange uma série de significados na realidade dos sécs. XIII-XV. Em primeiro lugar, o termo tem um sentido puramente material, físico, espacial de dirigir, de fazer ir em frente num determinado caminho ou estrada. Assim, "governar é seguir um caminho, ou fazer seguir um caminho" (FOUCAULT, 2002, p. 162) ${ }^{5}$. Tem-se ainda o sentido material, porém mais vasto, ligado à subsistência, de alimentar garantindo o sustento. Ainda dentro desse campo de sentido, fala-se de tirar sua subsistência de algo, de alguma coisa.

Em seguida, tem-se os significados de ordem moral. Assim, governar pode significar "conduzir alguém", tanto no sentido espiritual como no de imposição de um regime, como o caso de um médico que prescreve um regime a um doente. Dessa forma, governar se refere propriamente à conduta, ou ainda a uma relação entre indivíduos que assumem formas como de mando e chefia, ou mesmo uma relação verbal em que "governar alguém" pode significar "falar com alguém". Mas pode se referir, igualmente, a um comércio sexual.

$5 \quad$ Ibid., 162. 
Todas essas informações revelam o vastíssimo domínio semântico que abrange o termo "governar" antes de corresponder propriamente a uma questão política, a partir do séc. XVI. Todavia, para Foucault, existe algo de comum presente em todas essas formas de exercício do governo, a saber: "nunca se governa um Estado, nunca se governa um território, nunca se governa uma estrutura política.

Quem é governado são sempre as pessoas, são homens, indivíduos ou coletividades" (FOUCAULT, 2002, p. 164) ${ }^{6}$.

Neste momento nos encontramos no limiar de uma das descobertas importantes de Foucault a respeito da origem desse modelo de governo. Segundo ele, a ideia de que os homens são governáveis não é grega, tampouco romana. Na cultura grega é recorrente a metáfora do leme, do timoneio, do piloto, daquele que tem o leme para designar a atividade de quem está à frente da cidade (por exemplo na obra Édipo Rei), mas isso não corresponde ao governo dos homens, pois nesses casos o objeto de governo é a cidade e, apenas indiretamente, os homens.

Daí que, para Foucault, a ideia de um governo dos homens remonta ao Oriente, primeiro num Oriente pré-cristão e, depois, no Oriente cristão. Ademais, isso ocorre de duas formas: primeiro, sob a forma de uma ideia e organização de um poder de tipo pastoral; segundo, sob a forma da direção das consciências, da direção das almas (FOUCAULT, 2002 , p. 166) $)^{7}$. Foucault abordará apenas a primeira forma nessa aula.

Sobre a ideia e a organização de um poder pastoral, Foucault verifica que a ideia de uma autoridade (rei, deus, chefe) ser um pastor com relação aos homens, vistos como seu rebanho, é algo muito familiar em diversos locais do Oriente mediterrâneo, sobretudo, é claro, entre os hebreus. Todavia inclusive o faraó, no instante de sua coroação, recebe as insígnias de pastor. Não obstante, o termo designava também a relação dos deuses ou do deus com os homens. "O deus é o pastor dos homens" (FOUCAULT, 2002, p. 167) ${ }^{8}$. Disso resulta um certo tipo de relação entre o soberano e o deus, pois uma vez que ambos são pastores de homens, o rei é de certa forma o pastor subalterno a que

\footnotetext{
Ibid., 164.

Ibid., 166.

Ibid., 167.
} 
Deus confiou o rebanho dos homens e que deve, no fim do dia e do seu reinado, restituir a Deus o rebanho que the fora confiado.

Contudo, diz Foucault, foi de modo particular entre os hebreus que a ideia do pastoreio mais se desenvolveu e se intensificou. Isso porque, para esse povo, a relação pastor-rebanho denota quase que exclusivamente uma relação religiosa. A própria relação entre Deus e os hebreus é vista como de Pastor e rebanho. Assim, o termo é reservado a Deus, pois é Ele o verdadeiro pastor. “A relação pastoral em sua forma plena e [...] positiva, é, portanto, essencialmente a relação entre Deus e os homens. É um poder que tem o seu princípio, seu fundamento, [...] no poder que Deus exerce sobre seu povo" (FOUCAULT, 2002, p. $167-68)^{9}$.

Uma vez encontrada a origem elementar da noção de pastor que guia os homens como a seu rebanho, algo inimaginável na cultura grega, Foucault se propõe a apresentar quais os traços específicos desse poder pastoral. Segundo ele, em primeiro lugar, o poder do pastor se exerce sobre um rebanho e, mais especificamente, sobre um rebanho em seu deslocamento, no movimento que o faz caminhar de um lado para outro. Isso porque, diferente do deus grego que é territorial, o Deus hebraico caminha, se desloca e inclusive erra. Sua presença nunca é tão intensa como quando seu povo se desloca.

Em segundo lugar, o poder pastoral é fundamentalmente benfazejo. Isso quer dizer, antes de mais nada, que não se trata de um elemento dentre outros que caracterizam o poder pastoral. Muito pelo contrário. Fazer o bem, no poder pastoral, corresponde à sua razão de ser. E isso está intimamente ligado ao objetivo essencial desse tipo de governo, a saber, a salvação dos homens, do rebanho. Salvação essa que corresponde, incialmente, aos meios de subsistência. Por esse motivo, dirá Foucault, encontramos aqui uma terceira característica importante: a forma que o poder pastoral adquire não é, inicialmente, a manifestação de sua força e superioridade e sim de seu zelo, dedicação e aplicação infinita.

É exatamente por isso que o pastor é aquele que "zela" no sentido de realizar uma vigilância em vista do que pode ser feito de errado ou acontecer de nefasto. Por que isso? indagará Foucault. Porque o pastor

$9 \quad$ Ibid., 167-68. 
tem um encargo definido pelo fardo e a fadiga, toda sua preocupação é voltada para fora, para os outros. Nasce daí, aos olhos do filósofo, um poder cujo caráter é oblativo e até transicional. O pastor está a serviço do rebanho, deve ser o intermediário entre esse último e o pasto, a alimentação, a salvação, o que revela que o poder pastoral, em si, é sempre um bem.

Uma última característica apresentada por Foucault, e uma das mais significativas na linha do pensamento do autor, corresponde à ideia de que o poder pastoral é um poder individualizante. Sim, o pastor dirige todo um rebanho, porém só o faz bem na medida em que não haja nenhuma só ovelha que o escape. O pastor faz tudo pela totalidade do rebanho, mas igualmente para cada uma das ovelhas. Chegamos assim, dirá o filósofo, ao cerne do paradoxo do pastor que se revela de duas formas. De um lado, ele tem de estar vigilante sobre todos e cada um, omnes et singulatim, elemento esse paradigmático, tanto das técnicas de poder no pastorado cristão como das técnicas de poder modernas. De outro lado, e de forma ainda mais profunda, isso terá incidência no que se trata da questão do sacrifício do pastor em relação ao seu rebanho. Sacrifício dele pela totalidade e dessa por cada uma das ovelhas.

Nesse sentido, dirá Foucault, fala-se aqui de um poder que se exerce mais sobre a multiplicidade do que sobre um território. É um poder que guia para um determinado objetivo e serve como intermediário rumo ao mesmo. É, enfim, um poder que visa ao mesmo tempo todos e cada um em sua paradoxal equivalência e não uma unidade superior formada pela união do todo, como uma cidade, Estado etc. (FOUCAULT, 2002, p. 173) ${ }^{10}$.

Por último, segundo Foucault, se temos um determinado tipo de relação de poder tão alheio ao pensamento grego e romano é porque o mesmo foi introduzido no mundo ocidental por meio da Igreja cristã. Foi essa que coagulou todos esses temas de poder pastoral em mecanismos precisos e instituições definidas, organizou um poder pastoral igualmente específico e autônomo e implantou no interior do Império Romano seus dispositivos, articulando, no interior do mesmo, um tipo de poder que nenhuma civilização outrora havia conhecido. Assim, o

10 Ibid., 173. 
homem ocidental aprendeu durante milênios a se considerar uma ovelha entre outras e a pedir sua salvação a um pastor que se sacrifica por ele.

As características do paradigma judaico-cristão como base permanente do neoliberalismo e capitalismo de vigilância atuais

Uma vez compreendida a noção de governamentalidade, cunhada por Foucault, e a origem judaico-cristã do paradigma base dessa conduta dos homens, a pergunta que fica é: qual a pertinência desse estudo no tocante à reflexão em torno da realidade política atual? E a resposta não é outra, senão que, analisando "por detrás" do exercício de governo atual, o que se observa corresponde justamente à mesma lógica judaico-cristã, do Pastor que conduz as suas ovelhas, ou seja, de uma razão neoliberal que não mede forças para conduzir os seus indivíduos, a partir dos princípios de governo de um e de todos, da noção de liberdade, de culpa e da necessidade de um investimento contínuo sobre si mesmo (capital humano). Trabalhando com esses conceitos a nova razão do mundo consegue fazer-se mais do que assimilável pelos indivíduos, exercendo uma coação ainda mais profunda e silenciosa que outros sistemas ao longo da história.

Segundo alguns autores como Dardot e Laval, bem como Safatle, Junior e Dunker, percebe-se ainda hoje uma incompreensão do que realmente significa esse novo sistema socioeconômico neoliberal. Isso porque, diferentemente do que muitos pensam, não se trata de um liberalismo melhorado, resultado dos avanços históricos do séc. XIX, mas sim de um novo sistema, muito mais potente e devastador devido a sua capacidade de adaptação e manipulação das condutas. Ademais, nesse novo sistema o Estado não está excluso, mas, como afirma Safatle, Junior e Dunker, "em relação ao liberalismo clássico, o neoliberalismo representava muito mais intervenção do Estado.

A verdadeira questão era: onde o Estado efetivamente intervia [ou interviria]?" (2020, p. 22). Mas logo se encontrou a resposta: uma vez que o neoliberalismo precisa da liberdade como empreendedorismo e a livre-iniciativa,

"o Estado deveria intervir para despolitizar a sociedade, única maneira de impedir que a política intervisse na autonomia necessária de ação da economia. Ele deveria [...] retirar toda a pressão de instâncias, associações, instituições e sindicatos que visassem questionar tal noção de 
liberdade a partir da consciência da natureza fundadora da luta de classes" (SAFATLE; JUNIOR; DUNKER, 2020, p. 22) ${ }^{11}$.

Entretanto, para levar a cabo aquilo que pronunciou Margareth Thatcher: "Economia é o método. O objetivo é mudar o coração e a alma" (SAFATLE, JUNIOR E DUNKER, 2020, p. 21) ${ }^{12}$, era necessário passar do social ao subjetivo, ou seja, implementar junto às doses de intervenção do Estado, uma reeducação dos indivíduos, até o momento em que esses começassem a se autocompreender como "empreendedores de si" e internalizassem a racionalidade econômica neoliberal como a única forma de racionalidade possível.

Safatle, Junior e Dunker chamam isso de um profundo trabalho de design psicológico (2020, p. 21 grifo nosso) realizado pelo sistema neoliberal. Ou seja, de internalização de predisposições psicológicas visando a produção de um tipo de relação do sujeito consigo mesmo, com os outros e com o mundo, através da generalização de princípios universais de performance, investimento e rentabilidade para todos os meandros da vida. Tudo isso se torna possível através da repetição de discursos morais que nos fazem compreender qualquer oposição à lógica posta como falta moral, como recusa a assumir a vida adulta e ser responsável pelo próprio sucesso e/ou fracasso.

O cenário se agrava, sobretudo no século XXI, com a perfeita união entre neoliberalismo e as mídias sociais, bem como com as plataformas de buscas na Internet, com destaque para o gigante Google, que se tornou uma das principais ferramentas a serviço de um totalitarismo da lei da concorrência mercadológica no ciberespaço. Como propõe (ZUBOFF, 2020, p. 85) ${ }^{13}$, em sua análise presente na obra "A era do capitalismo de vigilância: a luta por um futuro humano na nova fronteira do poder", a principal plataforma de buscas, pensada nos primórdios como em favor da liberdade almejada na virada do milênio, tornou-se, na verdade, uma das principais empresas a conseguir um enorme acúmulo de capital por meio da vigilância e do controle.

\footnotetext{
11 SAFATLE. Vladimir. JUNIOR, Nelson da S. DUNKER, Christian (Org.). Neoliberalismo como gestão do sofrimento psíquico. Belo Horizonte: Autêntica, 2020.

12 Ibid., 21.

13 Ibid., 85.
} 
Ao coletar uma gama enorme de informações dos milhões de usuários que o utilizam, uma parcela é utilizada a serviço de uma melhor performance da própria ferramenta de buscas, ao passo que o chamado superávit comportamental (2020, p. 92-117) ${ }^{14}$, a saber, o excedente de informações coletadas, tornam-se dados decodificáveis por algoritmos, donde resulta um perfil individual bastante preciso de cada sujeito. Com essa "receita de ouro", o Google teria muito a oferecer às empresas de produtos e serviços, de modo que cada sujeito se tornaria um indivíduo bem conhecido em meio a massa e fácil, portanto, de ser "iscado" pelas propagandas, segundo seus interesses, opções e gostos, revelados pelos mesmos usuários.

Um exemplo concreto do tamanho do controle e da precisão de dados que esse gigante da tecnologia possui de cada um de nós, mesmo hoje, com a criação de leis que preservariam as informações dos usuários, pode ser encontrado em um artigo da Lieman Lab publicada na revista virtual Poder 360. Segundo essa matéria, um usuário havia aberto um processo judicial contra o Google, devido à falsa garantia de que esse último não teria acesso a localização das pessoas quando essas estivessem offline, ou mesmo quando desligassem o recurso "histórico de localização". Todavia não era isso o que acontecia de fato. Numa sessão de ajuda do website do Google, constava a informação de que desativar o "histórico de localização" não prejudicaria outros serviços de localização, e, inclusive, esses dados poderiam ser salvos por meio de outros serviços, como o Pesquisa e Mapas (LAB, 2018) ${ }^{15}$.

Uma nova pesquisa de Douglas Schimidt, como apresenta a matéria, descreve com mais detalhes um panorama de quais dados são coletados pelo Google. Segundo as pesquisas e os relatórios obtidos,

"um telefone Android inativo (com o navegador Google Chrome ativo em segundo plano) comunicou informações de localização ao Google 340 vezes durante um período de 24 horas, uma média de 14 comunicações de

14 Ibid., 173.

15 LAB, Nieman. Saiba como o Google está armazenando os dados de seus usuários. Poder 360, 27 de agosto de 2018. Disponível em: https://www.poder360.com.br/nieman/ saiba-como-a-google-esta-armazenando-os-dados-de-seus-usuarios/. Acesso em 26 de outubro de 2021. 
dados por hora. Na verdade, as informações de localização constituíram $35 \%$ de todas as amostras de dados enviadas por celulares à Google.

[...] um experimento semelhante descobriu que, em um dispositivo iOS com o Safari, mas não o Google Chrome, o Google não podia coletar nenhum dado apreciável, ao menos que um usuário estivesse interagindo com o dispositivo. Além disso, um telefone Android inativo com o navegador Google Chrome envia ao Google quase 50 vezes mais solicitações de dados por hora do que um telefone iOS ocioso rodando o Safari." (SCHIMIDT, Douglas. Google Data collection. Apud. LAB, 2018) ${ }^{16}$.

Todos esses dados, apesar de alarmantes, se tornam ainda mais ao passo que, segundo à pesquisa, foram realizados em telefones inativos, sem interação com o usuário. Nesse sentido, se levarmos em conta que o Brasil é o segundo país em que a população passa mais tempo online, o acesso de empresas como o Google às nossas rotinas, pode-se dizer, se torna quase que total.

Tudo revela, ainda que de modo incipiente, com que profundidade e precisão a razão neoliberal está incidindo sobre a vida e a consciência de todos e de cada um dos indivíduos em um determinado espaço, por meio de ferramentas muito eficazes e com aquilo que os próprios sujeitos revelam de si mesmos, deixando com que sejam governados nas suas relações consigo, com os outros e com o próprio ambiente, pautado pela lógica do poder neoliberal, da concorrência e do acúmulo de capital possível a poucos, mesmo que isso leve à morte de muitos.

Aqui, não se trata de demonizar os meios de comunicação em massa ou a própria tecnologia, mas, como ressalta Zuboff, se trata de reconhecer que toda essa noção de governamentalidade reinante consiste em uma invenção humana, o neoliberalismo é uma invenção humana, segundo interesses e privilégios muito bem delimitados. Dessa forma, é possível falar de um projeto performativo. Pois, tal lógica

"não atua meramente como coerção comportamental, ao modo de uma disciplina que regula ideias, identificações e visões de mundo. Ela molda nossos desejos, e, nesse sentido, a performatividade neoliberal tem igualmente efeitos ontológicos na determinação e produção de sofrimento. Ela recodifica identidades, valores e modos de vida por meio

\footnotetext{
${ }^{16}$ Ibid., 2018.
} 
dos quais os sujeitos realmente modificam a si mesmos, e não apenas o que eles representam de si próprios" (SAFATLE; JUNIOR; DUNKER. 2020, pp. $9-10)^{17}$.

\section{A governamentalidade e a ética da subjetivação}

De acordo com (CANDIOTTO, 2011, p. 107) ${ }^{18}$, a problematização das relações de poder pelo viés da governamentalidade introduziu descontinuidades no interior da analítica do poder foucaultiana; mas, concomitantemente, ela possibilitou estabelecer vínculos frutíferos entre duas linhas de investigação, aparentemente díspares, desde 1976. A primeira destas linhas está relacionada à série de trabalhos voltada ao domínio da conduta sexual, que se estendia dos modernos até os gregos, passando pelo cristianismo primitivo e medieval. Foucault elaborou diversas modificações nestas pesquisas, explicadas no início do volume II de História da sexualidade: o uso dos prazeres. Entretanto, neste livro, bem como no volume III da História da sexualidade: O cuidado de si, a ênfase recai nos processos éticos de subjetivação, resultantes da relação do indivíduo consigo mesmo e com os outros. Estes estudos, amplamente discutidos ao longo de sua elaboração nos Ditos e escritos, volume IV, foram interpretados ao modo de um refúgio de Foucault na ética antiga, após os impasses insolúveis de sua analítica do poder. A proposição da ética do governo de si teria como contrapartida o esvanecimento da confiança nas resistências e no engajamento político, bem como na démarche de sua microfísica do poder.

Sem embargo, outra linha de investigação observável a partir da publicação dos cursos no Collège de France, aponta para a improcedência da avaliação de que houvera um refúgio na ética dos antigos correlatos do abandono da política. Esta linha é composta de uma série de pesquisas sobre o biopoder e a segurança no canteiro histórico da luta entre as raças (1976); a genealogia da governamentalidade, desde o poder pastoral até o liberalismo, no intermeio dos quais foi objeto de preocupação a razão de Estado (1978); a reestruturação da biopolí-

17 Ibid., 2018.

18 CANDIOTTO, Cesar. A governamentalidade em Foucault: da analítica do poder à ética da subjetivação. O que nos faz pensar $n^{0} 31$, dezembro de 2011. Disponível em: http://oquenosfazpensar.fil.puc-rio.br/import/pdf articles/OQNFP 31 6 cesar_candiotto. pdf. Consulta realizada em: 5 de janeiro de 2022 . 
tica pela investigação do ordoliberalismo alemão e do neoliberalismo da Escola de Chicago (1979); a introdução da ideia de anarqueologia para a relação entre política e verdade (1980). Parte significativa da recepção crítica atual da obra de Foucault tem se apropriado das sendas deixadas pelas suas estratégias metodológicas para percorrer outros domínios como a teologia e o direito (Agamben) ou as diversas formas de imunização da sociedade (Esposito). Como Foucault tinha a intenção de publicar um livro sobre a governamentalidade política, causa estranheza o juízo de que sua trajetória pela ética antiga teria correspondido à deserção da política.

\section{Considerações finais}

Objetivou-se com o presente texto analisar a noção de governamentalidade apresentada por Foucault e o paradigma base que o caracterizava, por meio de uma síntese daquilo que ele apresentou na aula do dia oito de fevereiro de 1978, em um curso ministrado no Collège de France. Isso revelou que a origem do modelo base, que tornar-se-ia o mais pernicioso e incisivo de governo dos homens, proveio do ambiente judaico-cristão, da noção de Pastor que conduz as suas ovelhas, todas e cada uma delas. Modelo que foi assumido e utilizado no âmbito das relações políticas e sociais. Assim, a atualidade da presente análise se revela ao percebermos que, como propõe Foucault, a lógica que subjaz ao governo e aos assuntos a ele relacionados permanece sendo exercida com base na noção de governo de todos e de cada um, que vigia de modo constante para que nada dê errado, que ninguém se oponha à ordem estabelecida, mas em tudo siga, com o consentimento dos sujeitos, o governo estabelecido. Isso posto faz com que reflitamos melhor sobre como, de que modo, para quais finalidades e com base em que dispositivos estamos sendo governados hoje, a fim de que nossas condutas não sejam reflexos e resultados de manipulações, mas sim de sujeitos conscientes e autônomos. Afinal, esse sistema, tal como se apresenta, como sendo o único possível e existente, não o é quando conhecemos as suas mazelas e incoerências, além do fato de ser fruto de decisões humanas, o que deixa espaço para se pensar um futuro diferente, pautado sobre princípios como o do bem-estar social e de uma ética cristã da responsabilidade. 


\section{Referências}

FOUCAULT, M. Segurança, território e população. Tradução: Eduardo Brandão. São Paulo: Martins Fontes, 2008.

FOUCAULT, Michel. Segurança, território, população: curso dado no Collège de France (1977-1978). São Paulo: Martins Fontes, 2008. Aula do dia 8 de fevereiro, pp. 154-174.

LAB, Nieman. Saiba como o Google está armazenando os dados de seus usuários. Poder 360, 27 de agosto de 2018. Disponível em: https://www. poder360.com.br/nieman/saiba-como-a-google-esta-armazenando-os-dados-de-seus-usuarios/. Acesso em 26 de outubro de 2021.

SAFATLE. Vladimir. JUNIOR, Nelson da S. DUNKER, Christian (Orgs.). Neoliberalismo como gestão do sofrimento psíquico. Belo Horizonte: Autêntica, 2020.

ZUBOFF, Shoshana. A era do capitalismo de vigilância: a luta por um futuro humano na nova fronteira do poder. Rio de Janeiro: Intrínseca, 2020.

Submetido em: 10-1-2022

Aceito em: 20-1-2022 